\title{
Electrochemical Biosensors in Nonaqueous Solutions and Their Applications
}

\author{
Toshio NAKAMUra \\ Department of Chemistry, Faculty of Science, Shinshu University, Asahi, Matsumoto 390-8621, Japan
}

\begin{abstract}
This review first describes the invention of functional interfaces to promote biochemical redox reactions between substrates in dipolar aprotic solvents and enzymes or related compounds immobilized at the interface. The interfaces contain hydrophilic polymer membranes, a gold nanoparticle self-assembled electrode constructed by using rigid rod dithiols, and binary self-assembled monolayers composed of amino and carboxyl terminal groups. Other topics covered are: the electrochemical characterization of the hydrophilic polymer membrane; the development of biosensors to obtain reaction parameters of enzymatic and of electrochemical kinetics; and applications to the study of materials involved in metabolism.
\end{abstract}

(Received October 10, 2006; Accepted December 11, 2006; Published March 10, 2007)

1 Introduction and Background 253

2 Tyrosinase Immobilized PAA Membrane

$2 \cdot 1$ Study in acetonitrile

$2 \cdot 2$ Study in $N, N$-dimethylacetamide

$2 \cdot 3$ Effect of co-immobilized $\gamma$-cyclodextrin

2.4 Characterization of poly(acrylamide) membrane

3 A Gold Nanoparticle Electrode Immobilized on

4,4'-Bis(methanethiol)biphenyl

$3 \cdot 1$ Study for density control of gold nanoparticle

3.2 Application to voltammetric study of the interaction of $\mathrm{Co}(\text { phen })_{3}{ }^{3+}$ with DNA

254
3.3 Application to the tyrosinase immobilized electrode
4 Construction and Application of Binary Self- assembled Monolayers of Thioctic Acid and Thioctic Amide

4.1 Construction and voltammetry of immobilized cytochrome $c$

4.2 Application to biosensing of metabolismic materials in nonaqueous solution systems

5 Conclusions

6 References

\section{Introduction and Background}

Enzymes have been found to have numerous applications as practical and specific catalysts in chemical and pharmaceutical syntheses and as recognition elements in biosensors. Many studies on the use of enzymatic activity in nonaqueous solutions have been carried out after Dastoli and Price reported their investigation of the catalytic activities of xanthine oxidase suspended in several organic media. ${ }^{1}$ The discovery of enzymatic activity in organic solvents containing little or no water has expanded the use of enzymes still further. ${ }^{2-4}$ Some of the benefits of utilizing enzymes in nonaqueous solvents over the use of conventional aqueous reaction media include the high solubility of many hydrophobic substrates in such solvents, the suppression of various side reactions promoted by water, altered enzymatic selectivity, and the ability to control this selectivity with the solvent. Many studies have been carried out to obtain a better understanding of the so-called solvent effects due to organic solvent properties. ${ }^{5-13}$ Factors such as solvent hydrophobicity, ${ }^{14}$ solvent polarity, water content, ${ }^{15}$ and substrate hydrophobicity ${ }^{16}$ can affect the enzymatic reaction rate. It is also worth trying to find new enzymatic reaction systems for research and practical use, especially in dipolar aprotic solvents.

E-mail: toshion@shinshu-u.ac.jp
With regard to the basic properties of nonaqueous solution systems, a useful text is that of Izutsu. ${ }^{17}$ An electrode system made by immobilizing an enzyme in a hydrophilic polymer thin membrane adsorbed on a noble metal disk electrode made it possible to investigate conveniently the enzymatic activity occurring at the membrane-organic solution interface. ${ }^{18}$ An immobilization of functional materials utilized for tracing reactions is also described in this paper. A tyrosinase(Tyro)immobilized poly(acrylamide) (PAA) membrane platinum disk electrode was prepared and the electrochemical behaviors of $o$-hydroxybenzene derivatives in acetonitrile $(\mathrm{AN})^{19}$ and $\mathrm{N}, \mathrm{N}$ dimethylacetamide (DMA) ${ }^{20}$ were reported. Electrochemical characterization of PAA membrane coated on a gold disk electrode in AN was carried out, and it was shown that the membrane electrode has array properties. ${ }^{21}$ Because of the unique properties of nanoparticles (NP), recent investigations have focused on the development of enzyme-modified NPbased electrochemical biosensors. ${ }^{22-24}$ The ability of NPs to stabilize enzymes, and to improve the efficiency of immobilized enzymes is extremely useful when preparing biosensors. Moreover, other characteristics of NPs, such as their high surface-to-volume ratio, their high surface energy, and their ability to decrease the distance between enzyme and metal particles, may facilitate electron transfer between redox sites and the electrode surfaces. In our laboratory, a gold nonoparticle (GN) self-assembled electrode has been 
constructed by using 4,4'-bis(methanethiol)biphenyl (MTP), rigid rod dithiols, as a binder between a gold disk and GNs. ${ }^{25-27}$ Recently the construction of binary self-assembled monolayers (SAMs) of thioctic acid (T-COOH) and thioctic amide $\left(\mathrm{T}-\mathrm{NH}_{2}\right)$ modified electrodes was reported. ${ }^{28}$ The voltammetry of immobilized cytochrome $c$ (cyt $c$ ) on the modified electrode and the application to the biosensing of metabolismic materials in nonaqueous solution systems were also described. ${ }^{28,29}$

\section{Tyrosinase Immobilized PAA Membrane}

The enzymatic activity of Tyro in the PAA membrane on reaction with the catechol derivatives in $\mathrm{AN}$ and DMA was confirmed by cyclic voltammetry (CV) and amperometry; and maximum current, $i_{\max }$, and Michaelis constants, $K_{\mathrm{m}}$, were determined amperometrically.

The current obtained at the PAA-Tyro electrode was attributed to the reduction of the enzymatic reaction product, $o$-quinone. It was produced through the enzymatic oxidation of $o$-hydroxybenzene derivatives with dissolved oxygen at the boundary of the organic solvent and PAA membrane, then diffused to the surface of the platinum disk across the membrane before being reduced by the electrode.

The electrochemical system developed here can be used for tracing enzymatic reactions with substrates dissolving in aprotic solvents and for investigating solvent effects on enzymatic activities. It may also be possible to make better comparisons with batch methods both for smaller amounts and repeated use of enzymes. Cyclic voltammetric and amperometric measurements in this paper were carried out at $35^{\circ} \mathrm{C}$ with both a potentiostat/galvanostat by using the cell shown below,

$\mathrm{Ag} / 10 \mathrm{mM} \mathrm{AgNO}{ }_{3}+10 \mathrm{mM} \mathrm{Et}{ }_{4} \mathrm{NClO}_{4}(\mathrm{AN}) / / 50 \mathrm{mM}$ $\mathrm{Et}_{4} \mathrm{NClO}_{4}(\mathrm{D}) / / \mathrm{S}+50 \mathrm{mM} \mathrm{Et}_{4} \mathrm{NClO}_{4}(\mathrm{AN}) / \mathrm{PAA}$ or modified membrane + enzyme or functional materials/Pt or $\mathrm{Au}$

where $\mathrm{S}$ denotes substrates, metabolismic materials, and ferrocene $(\mathrm{Fc})$. D also denotes AN, DMA, glycerin (Gly), dimethylsulfoxide (DMSO), and $\mathrm{M}=\mathrm{mol} \mathrm{\textrm {dm } ^ { - 3 }}$. The schematic diagram of the emf measurement is shown in Scheme 1.

The reduction potentials of the substrates were reported $v s$. the cathodic peak potential of $\mathrm{Fc}$ as the pilot substance to standardize the reduction potentials obtained in aprotic solvents, to improve the reliability of potential data and to make possible the comparison of the potentials in the different solvents.

\section{$2 \cdot 1$ Study in acetonitrile}

Polymer coating on a metal disk electrode surface is an effective means of improving the function of an electrode surface. A modified platinum disk electrode coated with nonplasticized PAA membrane was used to study electrochemically the enzymatic reaction between Tyro immobilized in the PAA membrane and such substrates as catechol and 4-methylcatechol in AN. ${ }^{19}$ The enzymatic activity in the hydrophilic thin PAA membrane, which adhered to a platinum disk and was quite stable in the presence of the above substrates in AN, was confirmed by $\mathrm{CV}$ and amperometry. Maximum current densities, $i_{\max }$, Michaelis constants, $K_{\mathrm{m}}$, and turnover numbers were determined. The reduction potentials of the substrates were reported $v s$. the cathodic peak potential of $\mathrm{Fc}$ in AN.

\subsection{Study in $N, N$-dimethylacetamide}

Tyrosinase immobilized, hydrophilic PAA membrane electrode was successively used to investigate the enzymatic

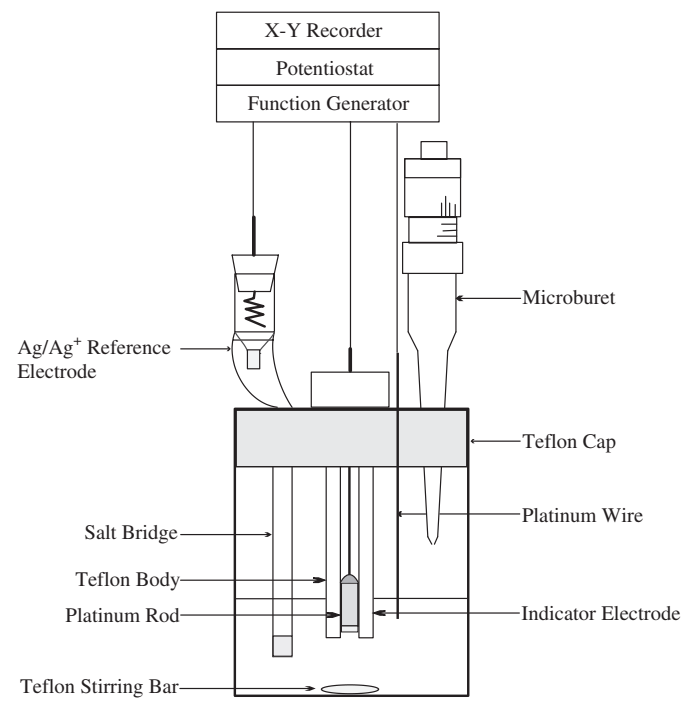

Scheme 1 Schematic diagram of emf measurement.

reaction of $o$-hydroxybenzene derivatives (4-methylcatechol, catechol, and biphenyl-2,3-diol) in DMA and Michaelis constants, $K_{\mathrm{m}}$, were obtained. The method can be used for monitoring both enzymatic activity and solvent effect by repeated use of a small amount of enzyme. ${ }^{20}$

To verify the catalytic properties of Tyro in a new environment, we immersed the PAA membrane in DMA at low water content $(<0.01 \% \mathrm{w} / \mathrm{w})$; then the effects of organic solvents on the enzymatic reaction and on the properties of the electrode were studied. Some possible kinetic factors related to the enzymatic reactions occurring in this new environment were proposed in the paper, and solvent effects due to dipolar aprotic solvents for these reactions are also described. The reduction potentials of the substrates were reported $v s$. the cathodic peak potential of Fc in DMA. It was concluded that the Tyro remains active because Tyro in the hydrophilic PAA membrane, which behaves as a so-called membrane protein, ${ }^{30}$ is naturally accustomed to a nonaqueous environment. The Michaelis constant $K_{\mathrm{m}}$ of Tyro in PAA for catechol was similar to that for the enzyme in aqueous solution. Figure 1 shows an example of the results obtained with the Pt/PAA + Tyro electrode. The electrode could be used to monitor solvent effects on enzyme activities and their reaction kinetics.

\section{$2 \cdot 3$ Effect of co-immobilized $\boldsymbol{\gamma}$-cyclodextrin}

A further study was conducted in order to improve sensitivity and voltammetric response of the electrode for enzymatic reactions between $o$-hydroxy derivatives with tyrosinase in dipolar aprotic solvents. Immobilization of $\gamma$-cyclodextrin $(\gamma$ CD) was performed by ripase catalized esterification of $\gamma$-CD with calboxyl modified-PAA. The enzymatic reaction may have been promoted at the three dimensional hydrophobic site established by $\gamma$-CD at PAA membrane. ${ }^{31}$ The CD immobilization increased the electrode response and enhanced the sensitivity. One of the results obtained with the Pt/PAA- $\gamma$ $\mathrm{CD}+$ Tyro electrode is shown in Fig. 2. An investigation into what caused such kinetic improvements is now being carried out at our research group using NMR from the perspective of molecular dynamics.

2.4 Characterization of poly(acrylamide) membrane

A number of ion selective electrodes were developed at our 


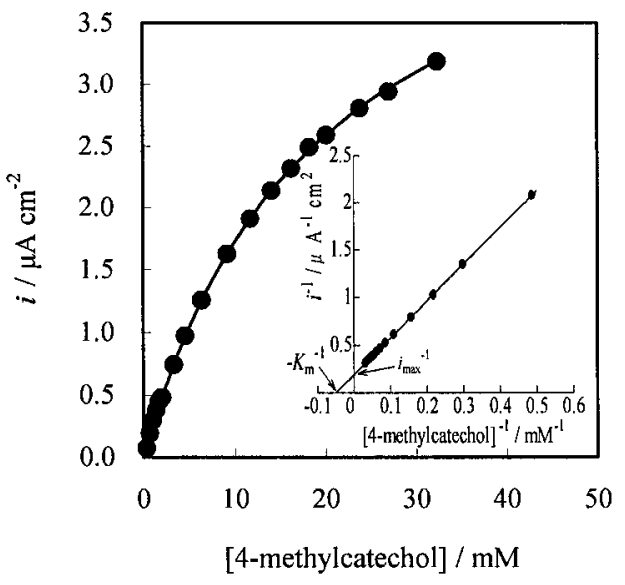

Fig. 1 Calibration plot of the PAA-tyrosinase electrode for 4methylcatechol in $50 \mathrm{mM} \mathrm{Et} \mathrm{NClO}_{4}-\mathrm{DMA}$ solution at $-0.900 \mathrm{~V}$. Inset: Lineweaver-Burk plot for the response of the PAA-tyrosinase electrode to 4-methylcatechol in DMA.

laboratory using a PAA membrane as matrix material for cation, ${ }^{32}$ anion, ${ }^{33}$ and biosensors ${ }^{19,20}$ for use in dipolar aprotic solvents and were employed both to study the thermodynamic properties of ion-solvent interactions $\mathrm{s}^{32}$ and to monitor solvent effects on enzyme activities and their reaction kinetics. ${ }^{19,20}$ Studies of the response mechanism of the electrodes were also carried out by voltammetry and spectrophotometry. ${ }^{32,33}$ We concluded that the PAA membrane possesses porous properties, and that gold and platinum electrodes modified with PAA membrane might yield microelectrode ensembles (MEEs) when the membrane is not too thick. It is important to clarify the character/properties of PAA membrane coated on the surface of electrode. The electrochemical behavior of PAA membrane in nonaqueous solutions was investigated by voltammetric and chronoamperometric experiments in order to characterize the function of the membrane electrode. ${ }^{21}$ The electrochemical behavior of an PAA membrane electrode, which had been worked as a sensing electrode matrix for use in nonaqueous solutions, was investigated in AN. It was found that PAA MEEs possess properties of microelectrode ensembles. For the thin PAA membrane, the PAA membrane electrodes behave similarly to a macroelectrode. Quantitative and semiquantitative analyses of the electrochemical response characteristics of these ensembles were conducted. The results showed that the electrochemical behavior of these ensembles agreed closely with predictions made on the basis of established microelectrode electrochemical theory. When the PAA polymer membrane electrode is used, the enzymatic reaction products at the boundary between the membrane surface and the solution go across the micro pore of the membrane, and are then diffused to the surface of the metal disk. Generally, nanoelectrode or microelectrode ensembles are prepared in several ways: (1) template synthesis method; 34,35 (2) the self-assembled monolayer (SAM); ${ }^{36,37}$ and (3) block copolymer self-assembly. ${ }^{38}$ Although these approaches are quite effective, they frequently become more complicated. The PAA membrane reported here can be used to fabricate microelectrode ensembles.

\section{A Gold Nanoparticle Electrode Immobilized on $4,4^{\prime}$-Bis(methanethiol)biphenyl}

A gold nanoparticle self-assembled electrode has been

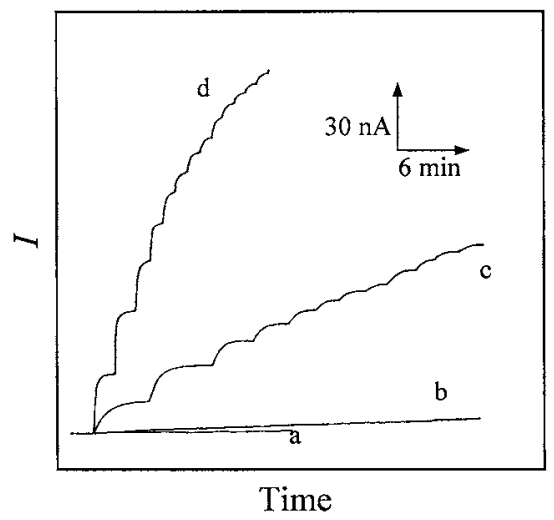

Fig. 2 Typical current-time response of (a) Pt/PAA- $\gamma-\mathrm{CD}$, (b) $\mathrm{Pt} / \mathrm{PAA}$, (c) $\mathrm{Pt} / \mathrm{PAA}+$ tyrosinase, and (d) $\mathrm{Pt} / \mathrm{PAA}-\gamma$-CD + tyrosinase electrodes on the stepwise addition of catechol from 0.90 to $13 \mathrm{mM}$ in $50 \mathrm{mM} \mathrm{Et}_{4} \mathrm{NClO}_{4}-\mathrm{AN}$ solution at $-0.80 \mathrm{~V}$.

constructed by using MTP, rigid rod dithiols, as a binder between a gold disk and NGs. ${ }^{25,26}$ We have devised a method of preparing density-controlled GNs self-assembled monolayer (SAM) interfaces by using both MTP and 1-octadecanethiol $(\mathrm{C} 18 \mathrm{SH})$ and have investigated their electrochemical behavior. The MTP forms assemblies in which one thiol group binds to the surface, while the other thiol moiety projects upward at the exposed surface of the SAM. There was no indication of inlooped structures. ${ }^{39}$ It was expected that the electrode based MTP would have applications in various biosensing situations. The effect of GNs on the interaction of $\mathrm{Co}(\mathrm{phen}) 3_{3}{ }^{3+}$ with DNA, and the characteristics of the electrode in a nonaqueous solution were described. An application of the MTP-based electrode, the construction of such a Tyro-modified GN-based gold disk electrode and an investigation of the voltammetric properties of the electrode to catechol in very low water content AN solution were also carried out. ${ }^{27}$

\section{3·1 Study for density control of gold nanoparticle}

The preparation and study of the electrochemical behavior of density-controlled GN self-assembled interface were carried out. A simple method was described for fabricating $\mathrm{GN}$ modified electrode, in which the density of GNs on the interface could be controlled by altering the abundance of SH-terminated thiols in the SAM. ${ }^{25}$ The binary SAMs were formed by MTP and $\mathrm{C} 18 \mathrm{SH}$ molecules coadsorbing simultaneously on gold electrode surface. The density of GNs on the interface could be controlled by altering the abundance of SH-terminated thiols in SAMs. There was no indication of in-looped structures in which both thiol ends were adsorbed to the surface, which may occur in flexible, long chain alkanedithiols. Scheme 2 shows the procedure for preparing density-controlled GN-SAM interfaces. Because GNs were adsorbed only on the -SH terminal group, the density of GNs in the SAM depended on the composition of the monolayer and the distribution of the MTP. The composition of the binary monolayer was changed by varying the ratio, $c_{\mathrm{C} 18 \mathrm{SH}} /\left(c_{\mathrm{MTP}}+c_{\mathrm{C} 18 \mathrm{SH}}\right)$, of MTP and $\mathrm{C} 18 \mathrm{SH}$ in the solution. We expect that the electrode based MTP will have various applications to biosensing in the future.

\subsection{Application to voltammetric study of the interaction of Co(phen $) 3^{3+}$ with DNA}

The effect of GNs on the interaction of tris(1,10phenanthroline)cobalt(III), $\mathrm{Co}(\text { phen })_{3}{ }^{3+}$, with DNA, and the 


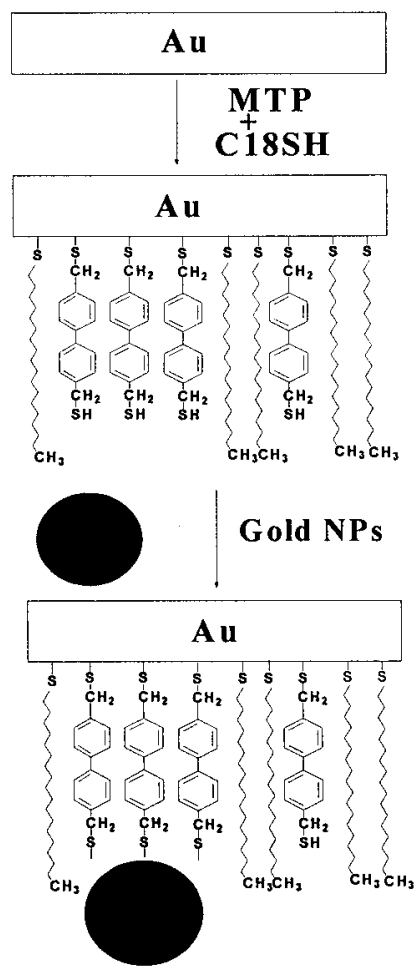

Scheme 2 The modification procedure for fabricating densitycontrolled gold nanoparticle (GN) self-assembled modified electrode.

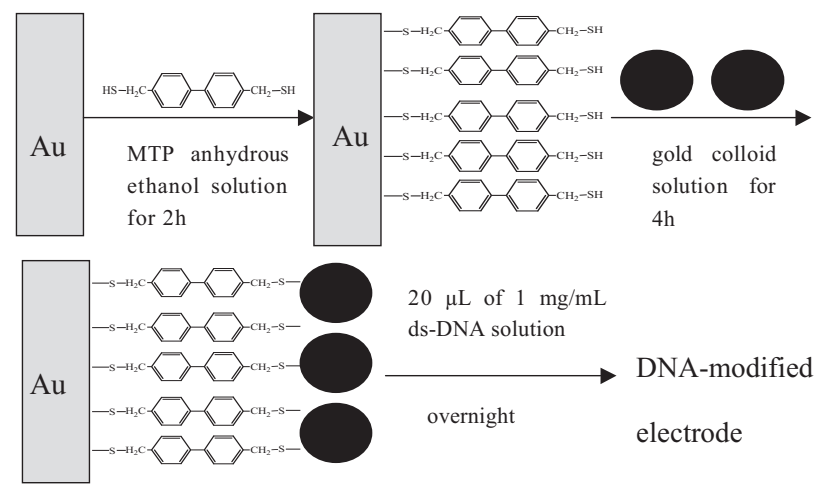

Scheme 3 Schematic diagram of the preparation of DNA modified electrode.

characteristics of the electrode in a nonaqueous solution were described. ${ }^{26}$ The paper demonstrated a new strategy for the immobilization of calf thymus DNA on the surface of GNs which were co-immobilized at a gold electrode through MTP molecule by an assembly process. The DNA modified electrode was incubated in $\mathrm{Co}(\text { phen })_{3}{ }^{3+}$ solution of aqueous buffer or an AN solution. Scheme 3 shows a schematic diagram of the preparation of DNA modified electrode. Clear redox peaks for $\mathrm{Co}($ phen $) 3^{3+}$ were observed both in an aqueous and AN solutions and Fig. 3 shows an example of CV response of the Au-MTPGNs + DNA + Co(phen $)_{3}{ }^{3+}$ electrode in AN. It was found that the surface coverage value of DNA molecules on modified GN and the redox current for adsorbed $\mathrm{Co}$ (phen) $3^{3+}$ decreased with the increasing size of GNs. In aqueous solution, the electron transfer rate constant for $\mathrm{Co}(\text { phen })_{3}{ }^{3+/ 2+}$ redox couple became slower with the increasing diameter of GN, and the speed had

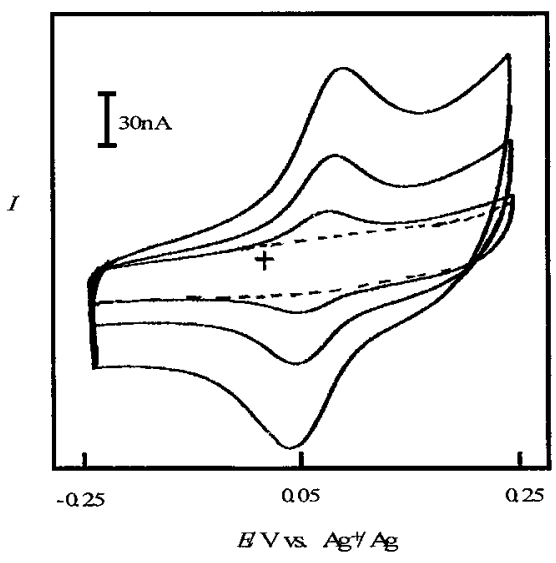

Fig. 3 Cyclic voltammograms of $\mathrm{Co}(\text { phen })_{3}{ }^{3+}$ adsorbed on DNA modified electrode in AN solution. Potential scan rates, $v=10,20$, $40 \mathrm{mV} / \mathrm{s}$; reference electrode, $0.01 \mathrm{M} \mathrm{Ag} / \mathrm{Ag}$. Dashed lines were obtained by using gold nanoparticle electrode (without ds-DNA) instead of DNA modified electrode $(v=10 \mathrm{mV} / \mathrm{s})$.

almost nothing to do with the diameter in nonaqueous solution. The surface concentration of $\mathrm{Co}($ phen $) 3^{3+}$ adsorption on DNA modified electrode decreased and the rate constant of adsorption kinetics increased with the increasing interactive temperature. In AN solution, the electrostatic interaction between DNA and $\mathrm{Co}(\mathrm{phen}) 3^{3+/ 2+}$ was greatly reduced. However, compared with the interaction in aqueous solution, the interaction between DNA and the reduced form of $\mathrm{Co}(\text { phen })_{3}{ }^{2+}$ was stronger than that with the oxidized form $\mathrm{Co}(\mathrm{phen})_{3}{ }^{3+}$. The surface concentration of $\mathrm{Co}(\mathrm{phen})_{3}{ }^{3+}$ adsorpted on DNA-modified electrode reached its maximum value at $20^{\circ} \mathrm{C}$, and the rate constant for the adsorption kinetics was nearly independent of the interactive temperature. The results show that the DNA on the modified electrode can adsorb effectively and that the $\mathrm{Co}(\mathrm{phen}) 3^{3+/ 2+}$ adsorbed on DNA gave good electrochemical responses both in aqueous and nonaqueous solutions. It was confirmed that the DNA-modified electrode could be used to investigate the interaction between DNA and electroactive species in both aqueous and nonaqueous systems. The differences in the ratio of the base pairs of DNA to $\mathrm{Co}$ (phen) $3^{3+12+}$ on the surface of the modified electrode may be due to the occurrence of only intercalative interactions between DNA and $\mathrm{Co}$ (phen $)_{3}{ }^{3+2+}$ in the AN system, while both intercalative interactions and electrostatic interactions occur in aqueous solution. The results also suggested that the electrostatic interaction between DNA and redox species was greatly weakened and that the intercalative interaction became dominant in $\mathrm{AN}$ solution.

\subsection{Application to the tyrosinase immobilized electrode}

The reactivity of Tyro adsorbed on GNs bound with MTP on a gold disk with catechol in AN was studied by $\mathrm{CV}$ and amperometric methods. ${ }^{27}$ Tyrosinase immobilized on GNs conjugated to a rigid rod dithiol remains active to the substrate in the dipolar aprotic solvent and exhibited characteristics of a Michaelis-Menten kinetic mechanism even when the water content was lower than $0.01 \mathrm{w} / \mathrm{w} \%$. The constant, $K_{\mathrm{m}}$, of Tyro for catechol was similar to that for the enzyme in aqueous solution $(5.5 \pm 0.4 \mathrm{mM})$. Furthermore, the electrode response was much faster than that of PAA-Tyro immobilized electrode. 


\section{Construction and Application of Binary Self- assembled Monolayers of Thioctic Acid and Thioctic Amide}

The electrochemistry of cyt $c$ at gold electrodes modified with single component SAMs of carboxylic acid terminated alkanethiols has been the subject of numerous studies. ${ }^{40-48}$ The SAMs have proven to be an excellent interface for the immobilization and electrochemical characterization of cyt $c$. The voltammetric response of cyt $c$ immobilized on the SAMs at gold electrode can be very stable and reproducible, but deviations from the expected response for an ideal adsorbed redox system have been observed. ${ }^{47}$ Especially, the voltammograms often display anomalous broadening. Recent studies have shown that certain types of binary SAMs have been known to exhibit random phase separation, making them highly conducive to cyt $c$ adsorption and electron transfer. ${ }^{49}$ The electrochemical response of cyt $c$ immobilized on binary SAMs composed of $\mathrm{COOH} / \mathrm{OH}^{49}$ and $\mathrm{COOH} / \mathrm{CH}_{3}{ }^{50,51}$ terminated alkanethiols were an obvious improvement on that observed for cyt $c$ immobilized on the single-component SAMs. Although alkanethiols with different chain lengths were used for such mixed terminated SAMs, it was not possible to improve the stability of the SAMs and to gain effective electron transfer at the same time.

On the basis of these studies, the combination of T-COOH and $\mathrm{T}-\mathrm{NH}_{2}$ was expected to have distinct advantages for gold electrode modification and immobilization of protein. The components of the terminal groups of the SAMs composed of $\mathrm{T}-\mathrm{COOH}$ and $\mathrm{T}-\mathrm{NH}_{2}$, amino and carboxyl, can match the residual groups $\left(-\mathrm{NH}_{2}\right.$ and $\left.-\mathrm{COOH}\right)$ of protein, making the interaction between SAMs and protein strong and the amount of adsorbed protein increase, because the interaction between SAMs and protein was promoted not only by electrostatic interaction but also by a steric effect and hydrogen-bond formation.

\subsection{Construction and voltammetry of immobilized cytochrome $c$}

Horse heart cyt $c$ was adsorbed on the binary SAMs composed of $\mathrm{T}-\mathrm{COOH}$ and $\mathrm{T}-\mathrm{NH}_{2}$ at gold disk electrodes via electrostatic interaction. Scheme 4 is a schematic diagram showing the immobilizing of cyt $c$ on the mixed SAMs of T$\mathrm{COOH}$ and $\mathrm{T}-\mathrm{NH}_{2}$ at a gold disk. The cyt $c$ adsorbed on the modified gold electrode exhibited well-defined reversible electrochemical behavior. The surface concentration of electroactive species, cyt $c$, on the binary SAMs was higher than that in single-component SAMs of T-COOH, and reached a maximum value when the ratio of $\mathrm{T}-\mathrm{COOH}$ to $\mathrm{T}-\mathrm{NH}_{2}$ in the adsorption solution was 3:2. The interaction between cyt $c$ and the binary SAMs made the formal potential shift negative compared with that of cyt $c$ in solution. The standard electron transfer rate constant of cyt $c$ immobilized on the binary SAMs was also higher than that for single-component SAMs of T$\mathrm{COOH}$ at the same ratio. The binary SAMs showed an effective electrochemical blocking of ferricyanide and ferrocyanide redox species and exhibited a similar relative percentage decrease in double layer capacitance. The SAMs formed in the adsorption solution at the ratio of 3:2 were the most conducive to cyt $c$ adsorption and electron transfer. The incorporated cyt $c$ was affected by the ionic strength and $\mathrm{pH}$ of solution, indicating the presence of electrostatic interaction between SAMs and cyt $c$. The results suggested that the electrode modified with the binary SAMs functions better than the electrode modified with single-component SAMs of T-COOH. ${ }^{28}$

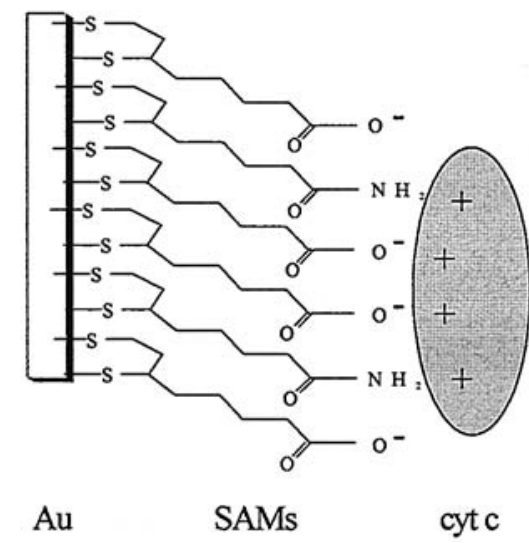

Scheme 4 Schematic diagram of immobilizing cyt $c$ on the mixed SAMs of T-COOH and $\mathrm{T}-\mathrm{NH}_{2}$.

\subsection{Application to biosensing of metabolismic materials in nonaqueous solution systems}

The quantitative detection of superoxide radical concentration in biological models is very difficult due to its fleeting existence and the low concentration. Most techniques for the detection of superoxide radical have used indirect spectroscopic methods, ${ }^{52}$ such as spectrophotometric measurement,${ }^{53}$ chemiluminescence method, ${ }^{54}$ and electron spin resonance spectroscopy. ${ }^{55}$ However, these means are ex situ detection techniques with poor selectivity or sensitivity.

A new amperometric microelectrode probe technique has been developed to detect superoxide radical both in vitro and in vivo. It was based on a promotor-modified gold electrode on which cyt $c$ was immobilized. ${ }^{56,57}$ Superoxide radical reduces the immobilized cyt $c$, which can be immediately reoxidized by the electrode at a suitable potential. The electrochemical method offers specific advantages, including a possibility of on-line measurement, minimum disturbance of chemical/enzymatic interventions, measurement in vivo, and low equipment cost.

Recently, single component $\mathrm{T}-\mathrm{COOH}$ momolayers ${ }^{58}$ and mixed-monolayers of short alkanethiols ${ }^{59}$ with immobilized cyt $c$ gold electrodes have been employed in the electrochemical detection of superoxide radical. However, amperometric sensors are limited both by the amount of cyt $c$ immobilized in the SAMs and the rate of electron transfer between cyt $c$ and the electrode. The sensitivity of the monolayer electrode was directly influenced by the surface density of protein on the electrode ${ }^{60}$ and the electron transfer rate between the electrode surface and cyt $c$. In order to broaden the range of applications, sensors have been developed for use not only in aqueous buffer but also in mixtures of aqueous and organic solvents. ${ }^{61}$

A new type of binary SAMs composed of T-COOH and T$\mathrm{NH}_{2}$ to modify the gold electrode mentioned above ${ }^{28}$ provided a superior gold surface for attaching cyt $c$. This was then used to develop a superoxide sensor in aqueous and organic/aqueous media. ${ }^{29}$ The sensor works by electrochemically detecting cyt $c$ reduced by the superoxide radical generated by a xanthine-XOD system. Scheme 5 shows the procedure for electrochemical reactions of $\mathrm{O}_{2}^{-}$at the cyt $c$ electrode in $40 \mathrm{v} / \mathrm{v} \%$ DMSO. The sensor responded to superoxide radical in $40 \%$ DMSO and in $30 \%$ Gly solution. The sensitivity of the sensors was 1.2 times higher in $40 \%$ DMSO than in PBS. The sensor could also be used to estimate SOD. The proposed method ${ }^{29}$ would provide on-line detection with relatively simple equipment, low costs, and high sensitivity, compared to chromatographic methods. 


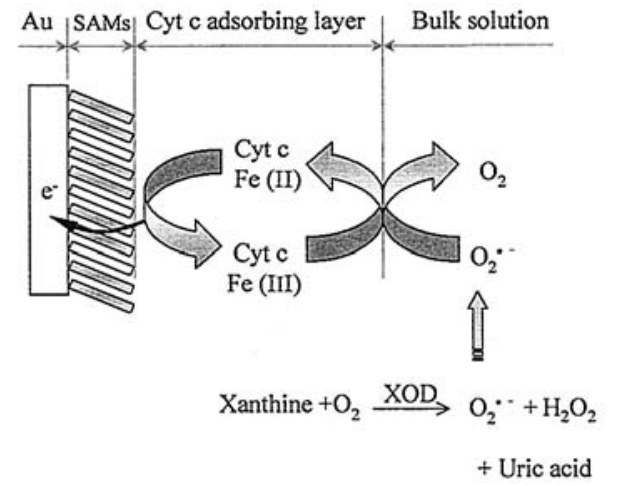

Scheme 5 Schematic diagram for electrochemical reactions of $\mathrm{O}_{2}$ at the cyt $c$ electrode in $40 \mathrm{v} / \mathrm{v} \%$ DMSO.

\section{Conclusions}

A hydrophilic polymer thin membrane, gold nanoparticle selfassembled electrodes constructed using MTP, and binary selfassembled monolayers of thioctic acid and thioctic amide were used to immobilize biofunctional materials. Characterization of the hydrophilic PAA membrane and the study of a gold nanoparticle density control were described.

The electrodes constructed here made it possible to investigate the enzymatic reaction kinetics occurring at the membrane-organic solution interface. The voltammetry of immobilized DNA and cyt $c$ on the modified electrode and application to metabolismic materials in aqueous/nonaqueous solution were also described.

\section{References}

1. F. R. Dastoli and S. Price, Arch. Biochem. Biophys., 1967, 118,163

2. S. J. Updike and G. P. Hicks, Nature, 1967, 214, 986.

3. A. M. Klibanov, Curr. Opin. Biotechnol., 2003, 14, 427.

4. A. M. Klibanov, Nature, 2001, 409, 241.

5. J. Wang, Y. Lin, and Q. Chen, Electroanalysis, 1993, 5, 23.

6. S. Dong and Y Guo, Anal. Chem., 1994, 66, 3895.

7. Q. Deng and S. Dong, Anal. Chem., 1995, 67, 1357.

8. J. Yu and H. Ju, Electroanalysis, 2004, 16, 1305.

9. S. Cosnier, C. Mousty, J. de Melo, A. Lepellec, A. Novoa, B. Polyak, and R. S. Marks, Electroanalysis, 2004, 16, 2022.

10. N. Adanyi, M. Toth-Markus, E. E. Szabo, M. Varadi, M. P. Sammartino, M. Tomassetti, and L. Campanella, Anal. Chim. Acta, 2004, 502, 219.

11. A. Konash and E. Magner, Anal. Chem., 2005, 77, 1647.

12. L. Campanella, G. Favero, M. P. Sammartino, and M. Tomassetti, J. Mol. Catal. B: Enzym., 1999, 7, 101.

13. P. Wang, S. Dai, S. D. Waezsada, A. Y. Tsao, and B. H. Davison, Biotechnol. Bioeng., 2001, 74, 249.

14. K. Yokoyama, M. Kawada, and E. J. Tamiya, J. Electroanal. Chem., 1997, 434, 217.

15. A. Zaks and A. M. Klibanov, J. Biol. Chem., 1988, 263, 3194.

16. P. P. Wangikar, T. P. Graycar, D. A. Estell, D. S. Clark, and J. S. Dordick, J. Am. Chem. Soc., 1993, 115, 12231.

17. K. Izutsu, "Electrochemistry in Nonaqueous Solutions", 2002, Wiley-VCH, Weinheim.
18. T. Nakamura and H. Nishikawa, Rev. Polarogr., 1990, 36 , 98; 1991, 37, 11; 1995, 41, 55; 1998, 44, 153; Bunseki Kagaku, 1997, 46, 45.

19. T. Miyasaka, Y. Takahashi, and T. Nakamura, Anal. Sci., 2001, 17, 1055.

20. J. Ren, H. Takeda, and T. Nakamura, Bull. Chem. Soc. Jpn., 2006, 79, 1410.

21. X. Ji, B. Jin, J. Ren, J. Jin, and T. Nakamura, J. Electroanal. Chem., 2005, 25, 579.

22. E. Katz, I. Willner, and J. Wang, Electroanalysis, 2004, 16, 19.

23. P. Yanez-Sedeno and J. M. Pingarron, Anal. Bioanal. Chem., 2005, 382, 884.

24. J. Kim, J. W. Grate, and P. Wang, Chem. Eng. Sci., 2006, 61, 1017.

25. B. Jin, S. Ding, K. Kametani, and T. Nakamura, Chem. Lett., 2005, 34, 302.

26. B. Jin, X. Ji, and T. Nakamura, Electrochim. Acta, 2004, 50,1049 .

27. T. Nakamura, J. Ren, K. Zhu, S. Kawara, and B. Jin, Anal. Sci., 2006, 22, 1261.

28. X. Ji, B. Jin, J. Ren, J. Jin, and T. Nakamura, J. Electroanal. Chem., 2006, 590, 173.

29. X. Ji and T. Nakamura, submitted.

30. P. Sundaresan, A. K. Sil, A. R. Philp, M. A. Randolph, G. Natchiar, and P. Namperumalsamy, Mol. Vis., 2004, 10, 1005.

31. T. Nakamura, X. Ji, K. Endo, and D. Takano, Chem. Lett., in press.

32. T. Nakamura and G. R. Rechnitz, Anal. Chem., 1985, 57, 393; T. Nakamura, K. Makino, M. Yanagisawa, and T. Miyasaka, Bull. Chem. Soc. Jpn., 1999, 72, 24; T. Nakamura and H. Mongi, Bull. Chem. Soc. Jpn., 1997, 70, 2449; J. Ren, J. Nakashima, and T. Nakamura, Bull. Chem. Soc. Jpn., 2006, 79, 291.

33. T. Nakamura, J. Ren, T. Hinoue, and K. Umemoto, Anal. Sci., 2003, 19, 991; J. Ren, H. Watanabe, S. Yamamura, and T. Nakamura, Anal. Chim. Acta, 2004, 525, 105.

34. Y. D. Jin and S. J. Dong, Communication, 2002, 1780.

35. V. P. Menon and C. R. Martin, Anal. Chem., 1995, 67, 1920.

36. O. Chailapakul and R. M. Crooks, Langmuir, 1995, 11, 1329.

37. E. Sabatani and I. Rubinstein, J. Phys. Chem., 1987, 91, 6663.

38. E. Jeoung, T. H. Galow, J. Schotter, M. Bal, A. Ursache, M. T. Tuominen, C. M. Stafford, T. P. Russell, and V. M. Rotello, Langmuir, 2001, 17, 6396.

39. J. M. Tour, L. Jones II, D. L. Pearson, J. J. S. Lamba, T. P. Burgin, G. M. Whitesides, D. L. Allara, A. N. Parikh, and S. Atre, J. Am. Chem. Soc., 1995, 117, 9529.

40. S. Song, R. A. Clark, E. F. Bowden, and M. J. Tarlov, J. Phys. Chem., 1993, 97, 6564.

41. M. Collinson, E. F. Bowden, and M. J. Tarlov, Langmuir, $1992,8,1247$.

42. M. J. Tarlov and E. F. Bowden, J. Am. Chem. Soc., 1991, $113,1847$.

43. T. M. Nahir and E. F. Bowden, J. Electroanal. Chem., 1996, $410,9$.

44. D. Zhang, G. S. Wilson, and K. Niki, Anal. Chem., 1994, 66, 3873 .

45. A. Avila, B. W. Gregory, K. Niki, and T. M. Cotton, J. Phys. Chem., 2000, B104, 2759.

46. Z. Q. Feng, S. Imabayashi, T. Kakiuchi, and K. Niki, J. Electroanal. Chem., 1995, 394, 149. 
47. R. A. Clark and E. F. Bowden, Langmuir, 1997, 13, 559.

48. M. C. Leopold and E. F. Bowden, Langmuir, 2002, 18, 2239.

49. A. E. Kasmi, J. M. Wallace, E. F. Bowden, S. M. Binet, and R. J. Linderman, J. Am. Chem. Soc., 1998, 120, 225.

50. D. Hobara, S. Imabayashi, and T. Kakiuchi, Nano Lett., 2002, 2, 1021 .

51. S. Arnold, Z. Q. Feng, T. Kakiuchi, W. Knoll, and K. Niki, J. Electroanal. Chem., 1997, 438, 91.

52. I. Fridovich, J. Biol. Chem., 1997, 272, 18515.

53. R. F. Haseloff, B. Ebert, and G. G. Wischnewsky, Anal. Chim. Acta, 1991, 243, 221.

54. S. Reichl, A. Vocks, M. Petkovic, M. Schiller, and J. Arnhold, J. Free Radic. Res., 2001, 35, 723.
55. J. R. Harbour and M. L. Hair, J. Phys. Chem., 1978, 82, 1397.

56. F. Lisdat, B. Ge, E. Ehrentreich-Forster, R. Reszka, and F. Scheller, Anal. Chem., 1999, 71, 1359.

57. C. J. McNeil, D. Athey, and W. O. Ho, Biosens. Bioelectron., 1995, 10, 75.

58. W. Scheller, W. Jin, E. Ehrentreich-Forster, B. Ge, F. Lisdat, R. Buttemeier, U. Wollenberger, and F. W. Scheller, Electroanalysis, 1999, 11, 703.

59. K. V. Gobi and F. Mizutani, J. Electroanal. Chem., 2000, 484, 172.

60. B. Ge and F. Lisdat, Anal. Chim. Acta, 2002, 454, 53.

61. M. Beissenhirtz, F. Scheller, and F. Lisdat, Electroanalysis, 2003, 15, 1425. 